mỗi tuần (mỗi thứ 2, thứ 4 và thứ 6 ) cho đến khi bệnh tiến triển và nhiễm độc độ 4 . Kết quả nghiên cứu tỉ lệ bệnh ổn định là $43 \%$, bệnh tiến triển $31 \%$, thời gian sống thêm không tiến triển là 4 tháng (2- 15 tháng), và thời gian sống còn toàn bộ là 7 tháng (3-24 tháng). Không có trường hợp tử vong được ghi nhận do độc tính điều trị, chỉ có 1 bệnh nhân có độc tính độ 3 bị mệt mỏi và tiêu chảy phải nhập viện [3]. Trong nghiên cứu của chúng tôi $12 / 23$ bệnh nhân có tuổi trên 60 . Kết quả cho thây nhóm bệnh nhân trên 60 và dưới 60 tuổi có kết quả điều trị không khác biệt. Tuy nhiên, những bệnh nhân thể trạng tốt $(E C O G 0,1)$ có kết quả vượt trội so với nhóm bệnh nhân ECOG $>1$ (12,4 tháng so với 5,4 tháng; $p=0,04$ )

Điều tri bước 2 và sau bước 2 cũng đã được đánh giá bởi tác giả . mặc dù các khuyến cáo điều trị không thực hiện thường quy các điều trị sau bước 2 . Tuy nhiên thực hành lâm sàng vẫn điều trị nếu có triệu chứng và tùy từng đối tượng bệnh nhân. Trong nghiên cứu này, mặc dù $79,6 \%$ bệnh nhân điều trị sau bước 2 nhưng cũng đạt được tỷ lệ ổn định bệnh gần 20\% [7]. Nghiên cứu của chúng tôi có $12 / 23$ bệnh nhân điêu trị sau bước 2 . Kết quả cho thấy sống thêm không tiến triển lâm sàng của nhóm này chỉ đạt 6,87 tháng, thấp hơn so với điều trị bước 2 .

\section{KẾT LUÂ̂N}

- Trung vị thời gian kéo dài lợi ích lâm sàng ECOG 0,1 là 12,4 tháng

- Trung vị thời gian kéo dài lợi ích lâm sàng ECOG $>1$ là 5,4 tháng

- Trung vị thời gian kéo dài lợi ích lâm sàng trên 60 tuổi là 6,87 tháng

- Trung vị thời gian kéo dài lợi ích lâm sàng dưới 60 tuổi là 8,57 tháng

- Trung vị thời gian kéo dài lợi ích ở bệnh nhân điều trị bước 2: Chưa đạt

- Trung vị thời gian kéo dài lợi ích ở điều trị sau bước 2: 6,87 tháng

\section{TÀI LIẸU THAM KHẢO}

1. Antonio $G$, Nicola $S$, Antonnela $L$, et al. (2015) "Metronomic chemotherapy from rationale to clinical studies: a dream or reality". Clinical reviews in Oncology/ Hematology 95 (2015) 46-61.

2. Magdalena K-W, Maciej K. (2016) "Metronomic chemotherapy in non - small - cell lung cancer current status" Oncol Clin Pract 2016; 12, 2: 37-42.

3. C. Bilir ,S. Durak B, Kızılkaya, et al. (2017) "Efficacy of metronomic vinorelbine in elderly patients with advanced non-small-cell lung cancer and poor performance status". Curr Oncol. 2017 June;24(3):199-204.

4. MichelaD'Ascanio, Aldo Pezzuto, Chiara Fiorentino (2018), "Metronomic Chemotherapy with Vinorelbine Produces Clinical Benefit and Low Toxicity in Frail Elderly Patients Affected by Advanced Non-Small Cell Lung Cancer". Hindawi BioMed Research International Volume 2018 Article ID 6278403, 6 pages https:// doi.org/10.1155/2018/6278403.

5. Andrea Camerini, et al, (2015) " Metronomic oral vinorelbin as first -line treatment in elderly patients with advanced non - small cell lung cancer: result of a phase II trial (MOVE trial)". BMC Cancer 2015, 15-359.

6. Camerini , Valsuani, Mazzoni, Siclari, (2010) "Phase II trials of single- agent oral vinorelbine in elderly ( $\geq 70$ years) patients with advanced non small cell lung cancer and poor performance status". Ann Oncol (2010) 21(6): 1290-1295.

7. Emmanouil Kontopodis, Dora Hatzidak, Ioannis Varthalitis, et al (2013). "A phase II study of metronomic oral vinorelbine administered in the second line and beyond in non-small cell lung cancer (NSCLC): a phase II study of the Hellenic Oncology Research Group" Journal of Chemotherapy 2013 VOL. 25 NO. 1, 49- 55.

\title{
TƯO'NG QUAN GIỮA ĐĂC ĐIÊM CARABELLI VÀ CHU VI THÂN RĂNG CỐI LỚN THỨ NHẤT VÀ THỨ HAI HÀM TRÊN TRONG ĐIỀU TRI NHA KHOA
}

\section{Huỳnh Kim Khang ${ }^{1}$, Trương Châu Bửu Lộc ${ }^{1}$}

\section{TÓM TẮT}

Mục tiêu: Xác định mối tương quan giữa mức độ biểu hiện đặc điểm Carabelli và chu vi thân răng cổi

\footnotetext{
${ }^{1}$ Đại họ Y Dược TP.Hồ Chí Minh

Chịu trách nhiệm chính: Huỳnh Kim Khang

Email: kimkhanghuynh@yahoo.com

Ngày nhận bài: 2/2/2021

Ngày phản biện khoa hoc: 29/2/2021

Ngày duyệt bài: 21/3/2021
}

lớn thứ nhất và thứ hai hàm trên. Phương pháp: Nghiên cứu cắt ngang phân tích, mẫu nghiên cứu gồm 45 răng cối lớn hàm trên (Carabelli độ 0 là 16 răng, dạng hố rãnh là 16 răng, dạng núm là 13 răng). Chu vi thân răng được xác định bằng cách vẽ một đường cong vòng theo đường viền của răng dựa trên ảnh chựp kĩ thuật số, đường viền được vẽ và đo đạc bằng phần mềm Autocad 2007 trên máy vi tính. Kết quả: Chu vi thân răng ở các hạng biểu hiện đặc điểm Carabelli là tương đối khác nhiau ở M1 lần lượt là hang $0(38,5 \pm 0,89)$ hang $1(39,6 \pm 1,32)$ hạng $2(40,7 \pm$ $1,4)$; ở M2 lần lượt là hạng $0(38,4 \pm 0,89)$ hạng 1 
$(39,7 \pm 1,39)$ hạng $2(40,8 \pm 0,56)$. Có mối tương quan thuận giữa chu vi thân răng cối lớn thứ nhất và thứ hai hàm trên với đặc điểm Carabelli lần lượt là 0,655 và $0,783(p<0,01)$. Kết luân: Có mối tương quan thuân giữa đặc điêm Carabelli và chu vi thân răng cối lớn thứ nhất và thứ hai hàm trên.

Tư khóa: Chu vi thân răng, răng cối lớn hàm trên.

\section{SUMMARY}

\section{CORRELATION BETWEEN THE CARABELLI TRAIT AND THE CROWN PERIMETER OF THE FIRST AND SECOND UPPER MOLARS IN DENTALTREATMENT}

Objectives: The aim of this study was to determine the correlation between the Carabelli trait and the crown perimeter of the first and second upper molars. Methods: With the cross - sectional and analytic study design, the sample consisted 45 upper molars (no Carabelli (16 teeth); pit, groove form (16 teeth); tubercular form (13 teeth)). Crown perimeter were determined by drawing a curve following the crown contour based on the digital image. The drawn contour is measured by Autocad software 2007. Results: The crown perimeter of the first and second upper molars were significant different $(p<0.05)$ between three Carabelli forms, respectively: no Carabelli (38.5mm and $38.4 \mathrm{~mm})$; pit, groove form $(39.6 \mathrm{~mm}$ and $39.7 \mathrm{~mm})$; tubercular form $(40.7 \mathrm{~mm}$ and $40.8 \mathrm{~mm}$ ). There were correlation between the crown perimeter of the first and second upper molars and Carabelli trait $(r=0.655$ and $r=0.783), p<0.01$. Conclusion: There were positivecorrelation between three Carabelli forms and the crown perimeter of the first and second upper molars.

Keyword: The crown perimeter, the upper molars Ký hiêu: RCL1, M1: răng cối lớn thứ nhất, răng cối lớn 1; RCL2, M2: răng cối lớn thứ hai, răng cối lớn 2; TB: trung bình, ĐLC: độ lệch chuẩn.

\section{I. ĐĂT VẤN ĐỀ}

Răng người và nhiều loài động vật khác nhau được tìm thấy ở hầu hết các di chỉ khảo cổ, do đó răng là đối tượng thuận lợi cho các nghiên cứu về con người. Bởi răng khó bị phá hủy trong lòng đất nên răng trở thành bộ phận có giá trị nhất của cơ thể trong các nghiên cứu về tiến hóa, nhân học. Do đó nghiên cứu hình thái răng giữ vai trò rất quan trong. Trong đó đặc điểm Carabelli xuất hiện khá phổ biến trong các nghiên cứu đặc điểm hình thái răng, được sử dụng trong pháp nha, nhân học răng và những nghiên cứu dân tộc [8].

Nhiều nghiên cứu được thực hiện nhằm xác định tỉ lệ biểu hiện của đặc điểm Carabelli cũng như mối liên hệ của nó đối với kích thước răng cối lớn hàm trền. Tuy nhiên vẫn còn có sự bất đồng giữa các tác giả về mối liên hệ giữa kích thước thân răng cối lớn hàm trên và đặc điểm Carabelli. Những nghiên cứu của Keene (1968),
Reid (1991), Harris (2007) cho thây có mối liên hệ giữa mức độ biểu hiện Carabelli và kích thước thân răng cối lớn thứ nhất hàm trên [2], [5], [7]. Garn và cộng sự (1966) đã kết luận rằng đặc điểm Carabelli là độc lập về mặt di truyền với kích thước răng hay hình thái thân răng [1].

Việc hiểu rõ sự hình thành và phát triển của đặc điểm Carabelli là cần thiết cho việc đánh giá tương quan của nó với những đặc điểm hình thái học khác của răng. Hơn thế nữa, cơ chế phát triển làm cơ sở cho biểu hiện của đặc điểm Carabelli có thể giống với sự hình thành của múi phụ cũng như sự hình thành múi răng nói chung.

Ở Việt Nam, việc nghiên cứu các đặc điểm hình thái trên răng cối lớn đã có từ khá lấu. Năm 1993, Hoàng Tử Hùng nghiên cứu về đặc điểm hình thái nhân học răng của người Việt [3]. Năm 2011, Huỳnh Kim Khang cũng đã đưa ra nghiên cứu về đặc điểm mẫu rãnh và Carabelli ở bộ răng sữa và bộ răng vĩnh viễn trẻ em người Việt [4]. Gần đây, trong thực hành lâm sàng, một số trường hợp chỉnh nha đặt khâu mắc cài ở răng cối lớn thứ nhất hàm trển không được do núm Carabelli lớn gây cản trở.Xuất phát từ thực tế đó, chúng tôi tiến hành nghiên cứu này với mục tiêu nghiên cứu là xác định mối tương quan giữa mức độ biểu hiện đặc điểm Carabelli và chu vi thân răng cối lớn thứ nhất và thứ hai hàm trên.

\section{II. ĐỐI TƯợNG VÀ PHƯƠNG PHÁP NGHIÊN CỨU}

2.1. Thiết kế nghiên cứu:Nghiên cứu cắt ngang phân tích.

2.2. Đối tượng nghiên cứu:Răng cối lớn thứ nhất và thứ hai hàm trên.

2.3.Tiêu chuẩn chọn mẫu:

Tiêu chuẩn chọn vào: Răng cối lớn thứ nhất và thứ hai hàm trên đã nhổ. Răng còn nguyên vẹn thân răng.

Tiêu chuẩn loại ra: Răng bị mòn mặt nhai nhiều. Răng bị võ̃ lớn mất các thành của thân răng.

2.4. Cỡ mẫu và chọn mẫu: 45 răng cối lớn hàm trên (Carabelli độ 0 là 16 răng, dạng hố rãnh là 16 răng, dạng núm là 13 răng)

2.5. Thu thập số liệu: Chụp ảnh kĩ thuât số mặt nhai của rằng cối lớn thứ nhất và thứ hai hàm trên với độ phân giải cao. Máy ảnh kĩ thuật số được cỗ định trên giá đỡ sao cho trục quang học của máy ảnh vuông góc với mặt phẳng ngang. Thân răng cối lớn hàm trên được đặt sao cho đường cổ răng của răng song song với mặt phẳng ngang và vuông góc với trục quang học của máy ảnh [6]. Răng được cố định bằng cách:

- Bước 1: Vẽ đường viền cổ răng trên răng thật.

- Bước 2: Đặt răng vào khuôn thạch cao sao 
cho đường viền cổ răng ở mặt ngoài song song với mặt phẳng ngang.

- Bước 3: Sau đó răng được chôn vào thạch cao theo hướng đã chọn, đế thạch cao được mài phẳng sao cho đế song song với mặt phẳng ngang.

Răng được đặt lên một mặt phẳng ngang vuông góc với ống kính của hệ thống chụp ảnh. Một thước đo milimét được đặt bên cạnh để việc đo đạc được chính xác hơn. Đồng thời, khoảng cách từ ống kính đến răng, ánh sáng, tiêu cự đều giống nhau cho các lần chụp. Trong nghiên cứu này chúng tôi tập trung vào chu vi của thân răng, chu vi thân răng được xác định bằng cách vẽ một đường cong vòng theo đường viền của răng dựa trên ảnh chụp kĩ thuật số, đường viền được vẽ và đo đạc bằng phẩn mềm Autocad 2007 trên máy vi tính.
2.6. Xử lý số liệu: Nhập số liệu bằng phần mềm SPSS 20.0. Phép kiểm ANOVA 1 chiều được sử dụng để phân tích những số đo chu vi thẩn răng giữa 3 hạng của đặc điểm Carabelli. Sử dụng hệ số tướng quan Spearman đề xác định tương quan giữa chu vi thân răng cối lớn thứ nhất, thứ hai hàm trên và các hạng của đặc điểm Carabelli..

2.7. Vấn đề y đức: nghiên cứu thực hiện trên các răng khô

\section{KẾT QUẢ NGHIÊN CỨU VÀ BÀN LUÂ̂N}

3.1. Chu vi thân răng cối lớn hàm trên. Chu vi thân răng ở các hạng biểu hiện đặc điểm Carabelli là tương đối khác nhau ở M1 lần lượt là hạng $0(38,5 \pm 0,89)$ hạng $1(39,6 \pm 1,32)$ hạng 2 $(40,7 \pm 1,4)$; ở M2 lần lượt là hạng $0(38,4 \pm 0,89)$ hạng $1(39,7 \pm 1,39)$ hạng $2(40,8 \pm 0,56)$ (Bảng 1$)$.

Bảng 1. Chu vi thân răng cối lớn hàm trên ở các hạng biểu hiện đặc điểm Carabelli (mm).

\begin{tabular}{|c|c|c|c|c|c|c|c|}
\hline \multirow{2}{*}{ Nhóm } & \multicolumn{2}{|c|}{ Hạng 0 } & \multicolumn{2}{c|}{ Hạng 1 } & \multicolumn{2}{c|}{ Hạng 2 } & \multirow{2}{*}{ P } \\
\cline { 2 - 6 } & TB & ĐLC & TB & DLC & TB & ĐLC & $0,003<0,05$ \\
\hline RCL 1 & 38,5 & 0,89 & 39,6 & 1,32 & 40,7 & 1,09 & $0,002<0,05$ \\
\hline RCL 2 & 38,4 & 0,89 & 39,7 & 1,4 & 40,8 & 0,56 & $0,002<$ \\
\hline
\end{tabular}

(Phép kiểm Anova 1 chiều)

Mối tương quan giữa chu vi thân răng cối lớn hàm trên và đặc điểm Carabelli.

Đặc điểm Carabelli với chu vi thân răng cối lớn hàm trên có sự liên quan có ý nghĩa thống kê, mối liên quan này biểu hiện gần như tương đương nhau ở răng cối lớn thứ nhất và thứ hai (Bảng 2).

Bảng 2. Mối tương quan giữa đặc điểm Carabelli và chu vi thân răng côi lớn hàm trên.

\begin{tabular}{|c|c|c|}
\hline Nhóm & $\begin{array}{c}\text { Hệ số } \\
\text { tương quan }\end{array}$ & $\mathbf{p}$ \\
\hline $\mathrm{RCL} 1$ & 0,655 & $0.00037<0,01$ \\
\hline $\mathrm{RCL} 2$ & 0,783 & $0.000045<0,01$ \\
\hline
\end{tabular}

- Mối tương quan giữa chu vi thân răng cối lớn thứ nhất hàm trên với đặc điểm Carabelli là tương quan thuận: 0,655, mức ý nghĩa $p<0,01$.

- Mối tương quan giữa chu vi thân răng cối lớn thứ hai hàm trên với đăc điểm Carabelli là tương quan thuận: 0,783, mức ý nghĩa $p<0,01$.

*Trong nghiên cứu này, chúng tôi khảo sát mối liên quan giữa một đặc điểm đo đạc là chu vi thân răng và đặc điểm Carabelli. Chu vi thân răng cối lớn thứ nhất và thứ hai hàm trên được thể hiện ở bảng 1 . Trong đó chu vi thân răng của răng có đặc điểm Carabelli ở dạng núm có kích thước lớn nhất, sau đó là răng có Carabelli dang hố rãnh và cuối cùng là răng không có biểu hiện đặc điểm Carabelli có kích thước nhỏ nhất. Sự phân bố kích thước này cũng tương tự ở răng cối lớn thứ hai hàm trên. Sự khác biệt về kích thước chu vi thân răng theo các mức độ biểu hiên đắc điểm Carabelli là khác biêt có ý nghĩa thống kê $(p<0,01)$. Chu vi thân răng ở răng cối lớn thứ nhất và thứ hai hàm trên có kích thước gần tương đương nhau.

Vodanovic và cộng sự (2013) nghiên cứu trên răng cối lớn thứ nhất ở người Crotia cho thấy có mối liên quan giữa đặc điểm Carabelli và kích thước ngoài trong thân răng (hệ số tương quan là 0,44 , mức ý nghĩa $\mathrm{p}<0,01$ ), và giữa kích thước gần xa thân răng với đặc điểm Carabelli (hệ số tương quan là 0,29 , mức ý nghĩa $\mathrm{p}<0,01$ ).

Trong nghiên cứu của chúng tôi, hê số tương quan giữa chu vi thân răng cối lớn thứ nhất hàm trên và đặc điểm Carabelli là 0,65 , mức ý nghĩa $p<0,01$. Do đó chu vi thân răng cối lớn thứ nhất hàm trên và các mức độ biểu hiện đặc điểm Carabelli là có tương quan thuận với nhau. ở răng cối lớn thứ hai, cũng có sự tương quan thuận giữa đặc điểm Carabelli và chu vi thân răng, với hệ số tương quan là 0,78 ở mức ý nghĩa $\mathrm{p}<0,01$. Nghiên cứu của chúng tôi tuy không sử dụng kích thước gần xa và ngoài trong như Vodanovic nhưng nó cũng cho thấy có mối liên quan giữa đặc điểm Carabelli và kích thước răng (chu vi thân răng). Ở răng có Carabelli thì chu vi thân răng sẽ lớn hơn ở răng không có Carabelli và đặc điểm Carabelli càng biểu hiện rõ thì chu vi thân răng đó càng lớn.

Trong thực hành nha khoa: các đặc điểm 
Carabelli càng rõ thì càng có nguy cơ sâu răng cao, hơn nữa việc khâu chỉnh nha không bù trừ được núm Carabelli làm tăng nhồi nhét thức ăn gây sâu răng, có thể dẫn đến giảm hiệu quả của việc điều trị chỉnh hình răng mặt. Kết quả nghiên cứu có thể giúp các nhà lâm sàng biết được các thay đổi kích thước răng khi quan sát các đặc điểm mô tả, đồng thời cung cấp thêm thông tin hữu ích về đặc điểm mô tả để các nhà lâm sàng có thể có được hướng xử trí thích hợp ví dụ như có thể suy nghĩ mài bớt núm Carabelli lớn cho phù hợp với khâu chỉnh nha hoặc trám bít hố rãnh Carabelli để phòng ngừa sâu răng...

\section{KẾT LUẬN}

Có sự tương quan thuận giữa đặc điểm Carabelli và chu vi thân răng cối lớn thứ nhất và thứ hai hàm trên.

\section{TÀI LIÊU THAM KHẢO}

1. Garn S. M, Lewis A. B, and Kerewsky R. S (1966), "Genetic independence of Carabelli's trait from tooth size or crown morphology", Archives of Oral Biology, 11, pp. 745-747.
2. Harris E. F. (2007), "Carabelli' Trait and Tooth Size of Human Maxillary First Molars", American Journal of Physical Anthropology, 132, pp. 238-246.

3. Hoàng Tử Hùng (1993), "Đăc điểm hình thái nhân học bộ răng người Việt", Luân án phó tiến sĩ khoa hợc Y dược, Trường Đại học Y Dược TP.Hồ Chí Minh, tr.1-63.

4. Huỳnh Kim Khang (2011), " Nghiên cứu dọc mối liên hệ một số đắc điểm hình thái giữa răng sữa và răng vĩnh viễn trẻ em người Việt", Luận án tiến sĩ khoa học $Y$ dược, tr.53-67.

5. Keene H. J. (1968), "The Relationship Between Carabelli' Trait and the Size, Number and Morphology of the Maxillary Molars", Archs Oral Biol, 13, pp. 1023-1025.

6. Levitan M.E, Himel V.T (2006), "Dens Evaginatus: LiteratureReview, Pathophysiology, and Comprehensive Treatment Regimen", Journal of Edondotics, 32, pp.1-9.

7. Reid C., Van Reeman J. F., and Groeneveld H. T. (1991), " Tooth Size and the Carabelli' Trait", American Journal of Physical Anthropology, 84 , pp. 427-432.

8. Sadatullah S., et al, (2012), "The Prevalence of Fifth Cusp (Cusp of Carabelli) in the Upper Molars in Saudi Arabian School Student", Int. J. Morphol, 30 (2), pp. 757-760.

\section{KẾT QUẢ PHÂN TÍCH DƯỚI NHÓM HÓA TRI VINORELBIN METRONOMIC NGHIÊN CỨU BÀO CHẾ VIÊN NANG TỪ BÀI THUỐC BÁT VỊ HOÀN}

\section{TÓM TẮT}

Mục tiêu: Bào chế bát vị ở dạng viên nang để chuẩn hóa liều dùng và thuận tiện khi sử dụng. Nguyên liêu và phương pháp: Các dược liệu được chế biến bẳng phương pháp nấu cao hoăc xay bộtt. Bột đóng nang là hỗn hợp gồm cao thục địa, sơn thù, trạch tả, phụ tử và bột mịn của bốn dược liệu còn lại và tá dược. Công thức viên nang cứng được xây dựng và chọn lựa dựa vào độ ẩm, tỷ trọng biểu kiến và độ trơn chảy của khối bôtt đóng nang. Kết quả: Đã bào chế được viên nang bát vị với liều dùng quy đổi là 3 viên/lần, ngày uống 2 lần. Tá dược độn được chọn là Avicel. Kết quả định tính cho thấy viên nang bát vị có phản ứng dương tính với các thuốc thử ứng với thành phần dược liệu và trên sắc ký đồ có các vết cùng giá trị $R_{f}$ và cùng màu sắc với các vết trên sắc ký đồ của dung dịch đối chiếu. Viên đạt yêu cầu về độ đồng đều khối lượng, độ rã theo chuyên luâan viên nang của DĐVN V. Kết luận: Viên nang bát vị đã được bào chế

${ }^{11}$ Trường Đại học Y khoa Phạm Ngọ Thạch Chịu trách nhiệm chính: Nguyễn Đăng Thoại Email: thoaind@pnt.edu.vn Ngày nhận bài: 20/1/2021

Ngày phản biên khoa học: 21/2/2021

Ngày duyệt bài: 15/3/2021 đat yêu cầu về chất lương của viên nang, có tác dụng bổ tỳ - thận dương, phù hợp để hỗ trợ điều trị cho người đau lưng, mỏi gối, chóng mặt, thuận tiện cho người sử dụng.

Tư khóa: Bát vi hoàn, bổ thận, đau lưng, nhức mỏi đầu gối, hoa mắt.

\section{SUMMARY \\ PREPARATION OF CAPSULE CONTAINING EXTRACT OF EIGHT MEDICINAL HERBS}

Objectives: To prepare bat vi in capsule form to standardize dosage and convenient to use. Materials and methods: The herbs were extracted by hot water or ground into powder. The filledpowdercomposed of extracts of Rehmannia glutinosa Libosch, Cornus officinalis Sieb. et Zucc, Alisma plantago-aquatica L. var. orientale Samuels, Aconitum Carmichaeli Debx. and powderof the other four medicinal herbs and some excipients. Moisture, density and smoothness of the powder were analyzed to select hard capsule formulations. Results: Bat vi capsules were prepared with an equivalent dose of 3 capsules/time, 2 or 2 times a day. Avicel was added to full-fill one capsule. As a result, capsules had a positive reaction to the reagents. On the chromatogram, there were traces of the same $R_{f}$ value and the same color as those on the chromatogram of reference medicinal herbs. Bat vi capsules meet the 